\title{
Corrigendum
}

\section{Advances in the use of bisphosphonates in the prostate cancer setting}

JP Coxon, GM Oades, KW Colston \& RS Kirby

Prostate Cancer and Prostatic Diseases (2004) 7, 270. doi:10.1038/sj.pcan.4500758

Correction to: Prostate Cancer and Prostatic Diseases (2004) 7, 99-104. doi:10.1038/sj.pcan.4500705

Since the publication of the above paper, the authors have identified an error in the Development of more modern bisphosphonates section. The original sentence had the figures reversed. The corrected sentence should read:
The median time to the first skeletal event was 321 days with placebo, and 488 days for patients receiving zoledronic acid $4 \mathrm{mg}(P=0.009)$. 